\title{
Development of an UPLC-MS/MS Assay to Determine Psoralidin in Rat Plasma and its Application in a Pharmacokinetic Study after Intragastric Administration
}

\author{
Feng Feng, Xiunan Jiang, Jieying Qiu, Hongyu Wu, Xiaojun Cai and Zheng Xiang* \\ School of Pharmaceutical Sciences, Wenzhou Medical University, Wenzhou 325035, China
}

Received: 11 Jul 2019; accepted: 07 Oct 2019

\begin{abstract}
Psoralidin has a variety of pharmacological activities, such as anti-tumor, anti-depressant, and anti-inflammatory activities. This study aims at developing a rapid ultra-performance liquid chromatography-tandem mass spectrometry (UPLC-MS/MS) method to determine psoralidin in rat plasma and studying the pharmacokinetic characteristic of psoralidin after intragastric administration of 20 and $40 \mathrm{mg} / \mathrm{kg}$. Alpinetin was used as an internal standard (IS), and the plasma samples were precipitated with acetonitrile. The calibration curves were linear over the range of $0.2-250 \mathrm{ng} / \mathrm{mL}\left(R^{2}=0.993\right)$. The pharmacokinetic parameters were calculated by DAS 3.0. Half-life $\left(t_{1 / 2}\right)$ was $7.2 \pm 0.97 \mathrm{~h}$ and $7.1 \pm 0.27 \mathrm{~h}$ for different dosages, respectively. $T_{\max }$ was $4.2 \pm 1.1 \mathrm{~h}$ and $4.0 \pm 1.1 \mathrm{~h}$ for different dosages, respectively. Apparent volume of distribution $\left(V_{\mathrm{d}}\right)$ for different dosages was $630.1 \pm 168.8$ and $600.1 \pm 138.8 \mathrm{~L} / \mathrm{kg}$, respectively. Clearance $(\mathrm{CL})$ was $105.6 \pm 29.2$ and $100.6 \pm 22.2 \mathrm{~L} / \mathrm{h} / \mathrm{kg}$ for different dosages, indicating that psoralidin was mainly distributed in rat tissues. The pharmacokinetic study provided important information for further clinical application in the treatment of cancer and osteoporosis.
\end{abstract}

Keywords: psoralidin, UPLC-MS/MS, pharmacokinetics

\section{Introduction}

Psoralen, a dried mature fruit of Psoralea corylifolia L., is a traditional medicine in China, India and other countries. Psoralidin is derived from Chinese medicine P. corylifolia L [1]. It is reported that psoralidin also has multiple pharmacological activities such as anti-tumor [2-7], anti-osteoporosis [8-12] and enhancement of immunity [13-15]. Studies have shown that psoralidin can release a large amount of $\mathrm{Ca}^{2+}$ in the endoplasmic reticulum by promoting the release of IP3, triggering the opening of mitochondrial permeability transition (PT) pores, and finally inducing apoptosis of human hepatoma HepG2 cells [16]. Szliszka et al. [17] propose that psoralidin can sensitize tumor necrosis factor (TNF)-related apoptosis-inducing ligand (TRAIL) to antagonize cells and significantly enhance TRAIL to regulate apoptosis of $\mathrm{LNCaP}$ prostate cancer cells. Psoralidin can also induce cells to produce reactive oxygen species (ROS), thereby inducing DNA damage and autophagy in breast cancer MCF-7 cells [18]. Jin et al. [19] demonstrates that psoralidin can inhibit the proliferation and enhance apoptosis of human esophageal cancer cells by affecting NF-0202B and PI3K/Akt signaling pathways. Wang's study indicates that psoralidin has antioxidant activity and $\alpha$-glucosidase inhibitory activity [20]. Li's preliminary studies [21] show that psoralidin can affect the bone mineral density and trabecular bone area ratio and has an anti-osteoporosis effect.

High-performance liquid chromatography-tandem mass spectrometry (HPLC-MS/MS) has been successfully applied to the determination of psoralidin in biological matrix. Yang et al. develop a liquid chromatographic-tandem mass spectrometry (LC-MS/MS) method for determination of psoralidin in rats after oral (PO) administration of Fructus Psoraleae extracts [22]. A HPLC-MS/MS method was also established to determinate psoralidin in rat plasma after intravenous (IV) administration of psoralidin $(2 \mathrm{mg} / \mathrm{kg})$ [23]. However, the reten-

*Author for correspondence: XZH0077@126.com; Tel/Fax: 86-577-86689949. tion time of psoralidin in two methods is more than $14 \mathrm{~min}$, and there is no pharmacokinetic report after intragastric administration of psoralidin. In fact, as for traditional Chinese medicines (TCMs), it is of more clinical value to study the intragastric pharmacokinetic characteristics of monomer. This work aims to develop a rapid ultra-high performance liquid chromatography-tandem mass spectrometry (UPLC-MS/MS) method for the determination of psoralidin in rat plasma and its pharmacokinetic properties after intragastric administration of 20 and $40 \mathrm{mg} / \mathrm{kg}$.

\section{Experiments}

2.1. Chemicals and Reagents. Psoralidin ( $>99.5 \%)$ and alpinetin (98.8\%, internal standard [IS]) were obtained from Chengdu Must Bio-Technology Co. Ltd. (Chengdou, China). HPLC-grade methanol and acetonitrile were purchased from Merck (Merck, Darmstadt, Germany). Ultra-pure water for the mobile phase was prepared using a Milli-Q system (Millipore, Bedford, MA, USA). Other reagents were of analytical grade.

2.2. Instrument and Chromatographic Conditions. Chromatographic separation was performed on an UPLC Acquity C18 $(1.8 \mu \mathrm{m}, 2.1 \mathrm{~mm} \times 100 \mathrm{~mm})$ column. Column temperature was maintained at $35{ }^{\circ} \mathrm{C}$, and the temperature of the autosampler was set at $4{ }^{\circ} \mathrm{C}$. The gradient mobile phases consisted of solvent A $(0.1 \%$ formic acid $)$ and solvent $\mathrm{B}$ (acetonitrile) as follows: $10 \% \mathrm{~B}$ from $0 \mathrm{~min}$ to $0.2 \mathrm{~min}, 10 \%$ to $80 \% \mathrm{~B}$ from $0.2 \mathrm{~min}$ to $1.5 \mathrm{~min}, 80 \% \mathrm{~B}$ from $1.5 \mathrm{~min}$ to $2 \mathrm{~min}, 80 \%$ to $10 \% \mathrm{~B}$ from $2 \mathrm{~min}$ to $2.2 \mathrm{~min}$, and $10 \% \mathrm{~B}$ from $2.2 \mathrm{~min}$ to $4 \mathrm{~min}$. The flow rate was $0.35 \mathrm{~mL} / \mathrm{min}$, and the injection volume was $5 \mu \mathrm{L}$.

Mass spectrometric detection was performed on a Micromass Quattro Micro triple quadrupole tandem mass spectrometer interfaced with an electrospray ionization (ESI) source. The ESI source was set to the positive ion mode. The optimized MS parameters were as follows: capillary voltage,

This is an open-access article distributed under the terms of the Creative Commons Attribution-NonCommercial 4.0 International License (https://creativecommons.org/licenses/by-nc/4.0/), which permits unrestricted use, distribution, and reproduction in any medium for non-commercial purposes, provided the original author and source are credited, a link to the CC License is provided, and changes - if any - are indicated. 
$1.93 \mathrm{kV}$; cone voltage, $33 \mathrm{~V}$; desolvent gas, nitrogen; desolvation temperature, $600{ }^{\circ} \mathrm{C}$; collision gas, argon; desolvation and cone gas, nitrogen; and collisions energy (CE), $30 \mathrm{~V}$. The cone voltage and collision energy of the IS were $30 \mathrm{~V}$ and $20 \mathrm{~V}$, respectively. Psoralidin and the IS were quantified via multiple reaction monitoring (MRM) of the ion transitions of $\mathrm{m} / \mathrm{z}$ $337.1 \rightarrow 209$ and $m / z 271.1 \rightarrow 123.9$, respectively (Figure 1). Data was processed using Waters MassLynx V4.1.

2.3. Preparation of Stock and Working Solutions. Stock solutions of psoralidin $(0.9 \mathrm{mg} / \mathrm{mL})$ and alpinetin (IS, $0.7 \mathrm{mg} /$ $\mathrm{mL}$ ) were precisely prepared by dissolving in methanol. The stock solution was then serially diluted in methanol to prepare desired working solutions. The concentrations of plasma calibration standards $(0.4,2,4,8,20,40,80,200$, and $400 \mathrm{ng} / \mathrm{mL}$ ) were prepared by adding suitable amounts of the working solutions to $100 \mu \mathrm{L}$ of blank plasma. Three levels of quality control samples (QCs) at low $(0.4 \mathrm{ng} / \mathrm{mL})$, medium (5 ng/mL), and high concentrations (200 ng/mL) for psoralidin and $100 \mathrm{ng} / \mathrm{mL}$ for the IS were prepared in blank plasma. All samples were stored at $-20{ }^{\circ} \mathrm{C}$ until analysis.

The blood samples were collected in $1.5-\mathrm{mL}$ heparinized centrifuge tubes and centrifuged at $4000 \mathrm{rpm}$ for $10 \mathrm{~min}$ to obtain plasma samples. Rat plasma was thawed at room temperature before use. Afterward, $100 \mu \mathrm{L}$ of aliquot of plasma samples and $10 \mu \mathrm{L}$ of the IS solution were pipetted into 1.5$\mathrm{mL}$ Eppendorf (EP) tubes and mixed for $30 \mathrm{~s}$. A $300 \mu \mathrm{L}$ acetonitrile was added and mixed by vortexing for $2 \mathrm{~min}$. The samples were centrifuged at $10,000 \mathrm{~g}$ for $15 \mathrm{~min}$ at $4{ }^{\circ} \mathrm{C}$, and $5 \mu \mathrm{L}$ of aliquot of the supernatant was injected into an UPLC system for analysis.

2.4. Method Validation. The method was validated in terms of selectivity, recovery, matrix effects, accuracy, linearity, precision, and stability according to the lasted United States Food and Drug Administration guidelines [24]. Selectivity was investigated by preparing and analyzing 6 individual blank plasma samples with the corresponding plasma samples spiked with psoralidin and the IS, and with plasma samples after administration. The linearity of the calibration curve was determined by plotting the peak area ratios of psoralidin-IS (y) vs. concentration of psoralidin $(x)$. The limits of detection (LOD) and quantification (LOQ) were calculated using the formulas $\mathrm{LOD}=3.3 \times \mathrm{SD} / a$, and $\mathrm{LOQ}=10 \times \mathrm{SD} / a$, respectively, where $\mathrm{SD}$ is the standard deviation of the peak height taken as a measure of noise, and $a$ is the slope of the corresponding calibration curve $(y=a x+$ $b$ ). The matrix effect was investigated by comparing the peak areas of the analytes in the post-extraction spiked blank plasma at low, medium, and high concentrations with those of the corresponding standard solutions. Extraction recoveries were determined by comparing the mean peak areas of the 6 extracted samples at low, medium, and high concentrations with those of spike-after-extraction samples. Intra-day precision and accuracy were evaluated by analyzing 6 replicates of QC samples at 3 different concentrations in the same day. Inter-day precision and accuracy were evaluated by analyzing 3 replicate QC samples at 3 different concentrations on 5 consecutive days. The stabilities of the QC samples at room temperature for $12 \mathrm{~h}$, at $4{ }^{\circ} \mathrm{C}$ for $24 \mathrm{~h}, 3$ freeze-thaw cycles, and storage at $-20{ }^{\circ} \mathrm{C}$ for 2 weeks were assessed by analyzing 3 replicate samples at 3 different concentrations.

2.5. Pharmacokinetic Analysis. Twelve male SD rats $(200 \pm 20 \mathrm{~g})$, which were $7-8$ weeks old, were provided by the Experimental Animal Center of Wenzhou Medical University. Rats were placed at a relative humidity of $55 \pm 10 \%$ and a temperature of $22 \pm 2{ }^{\circ} \mathrm{C}$. The rats were exposed to a 12/12-h light/dark cycle. The ethical approval of the study was obtained from the Animal Care and Ethics Committee of Wenzhou Medical University (July 20, 2017; No: 2017-250). Psoralidin was dissolved in sodium carboxymethyl cellulose and administered to the rats via intragastric routes $(20 \mathrm{mg} / \mathrm{kg}$ and $40 \mathrm{mg} / \mathrm{kg})$. The 12 rats were subjected to fasting for $12 \mathrm{~h}$ but were provided free access to water before the experiments were performed. Blood samples (approximately $0.3 \mathrm{~mL}$ ) were collected at $0.167,0.333,0.667$, $1,2,4,8,12$, and $24 \mathrm{~h}$ post-administration and stored in sodium heparin-containing tubes. All blood samples were collected from the tail vein. Pharmacokinetic parameters of psoralidin were calculated using DAS 3.0.

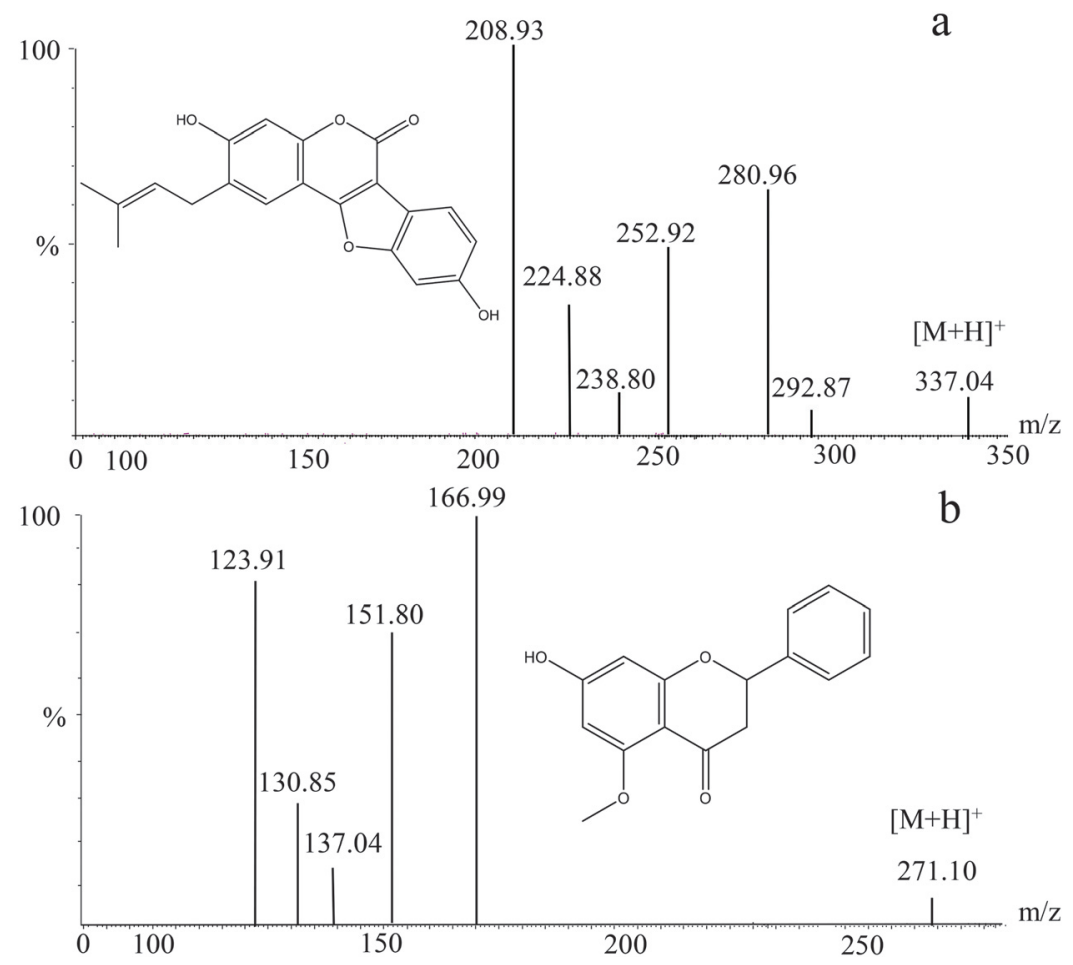

Figure 1. Mass spectra of psoralidin (a) and alpinetin (b) in the scan mode with an ESI (+) source 

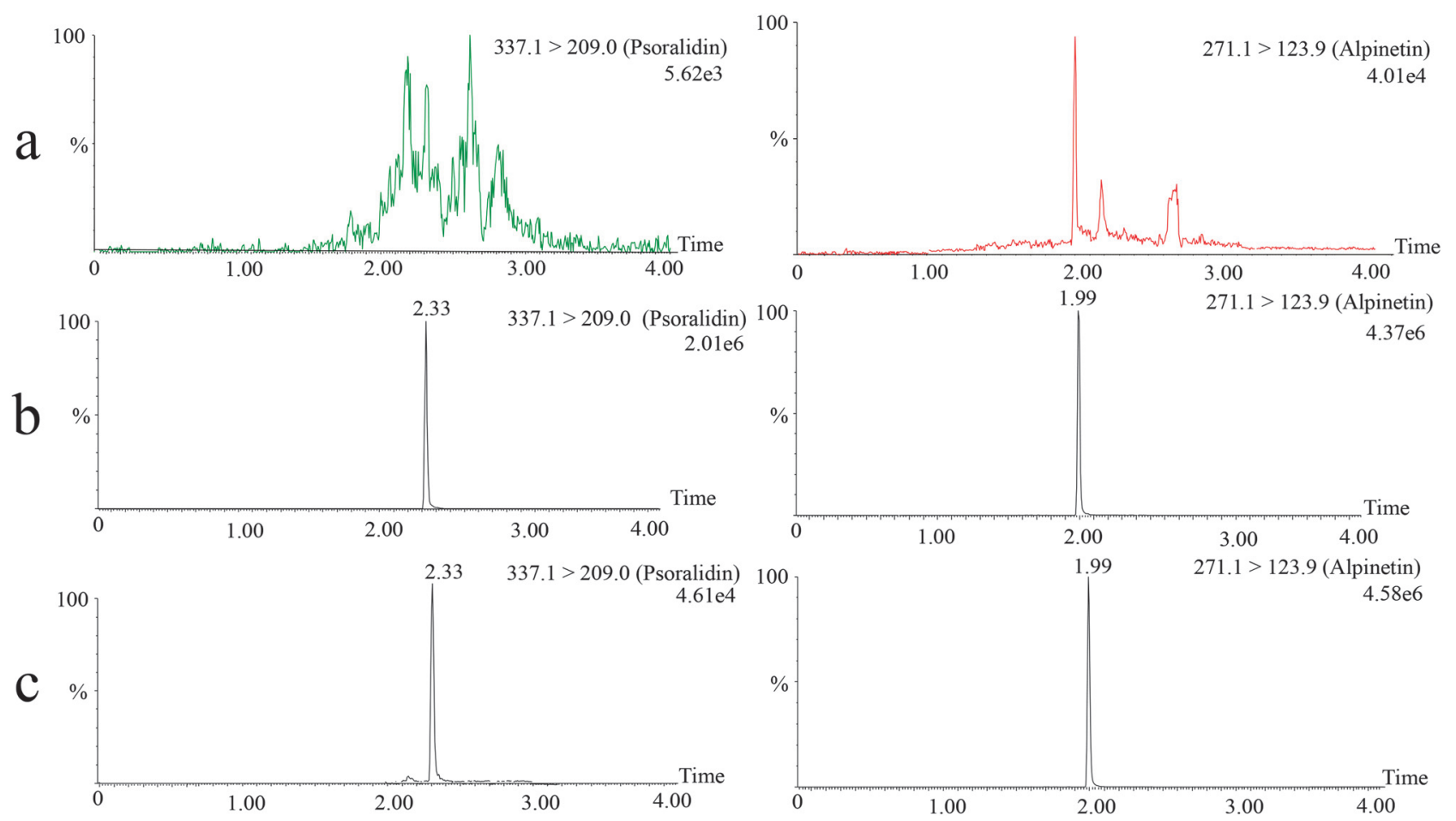

Figure 2. Representative chromatograms of blank plasma (a), plasma spiked with $50 \mathrm{ng} / \mathrm{mL}$ psoralidin and $100 \mathrm{ng} / \mathrm{mL}$ alpinetin (b), and plasma sample obtained 40 min after intragastric administration of psoralidin (c)

\section{Results and Discussion}

3.1. Method Development. The electrospray ionization (ESI) modes including positive $\left(\mathrm{ESI}^{+}\right)$and negative $\left(\mathrm{ESI}^{-}\right)$ were used to select precursor ions at $\mathrm{m} / \mathrm{z}$. The result indicated that $\mathrm{ESI}^{+}$exhibited a higher response value of ions than $\mathrm{ESI}^{-}$. Psoralidin and the IS yielded the precursor ions of $\mathrm{m} / \mathrm{z} 337.1$ and $\mathrm{m} / \mathrm{z}$ 271.1, respectively. The product ions of $\mathrm{m} / \mathrm{z} 209$ and $\mathrm{m} / \mathrm{z} 123.9$ of psoralidin and the IS were selected, respectively (Figure 1). Acetonitrile, methanol, water, and formic acid in water were evaluated to determine the optimal mobile phase. Acetonitrile and $0.1 \%$ formic acid were selected as the mobile phases because these substances exhibited lower column pressures, sharper peak shapes, and higher sensitivities than those of combination of both methanol and water. Retention time of psoralidin was $2.3 \mathrm{~min}$, and it was shorter than that of references ( $>10 \mathrm{~min})$ [22-23]. Protein precipitation and liquid-liquid extraction were also evaluated. The results

Table 1. Extraction recovery and matrix effect of psoralidin in rat plasma $(n=6)$

\begin{tabular}{lcc}
\hline $\begin{array}{l}\text { Spiked plasma } \\
\text { concentration }(\mathrm{ng} / \mathrm{mL})\end{array}$ & $\begin{array}{c}\text { Extraction recovery } \\
(\text { mean } \pm \mathrm{SD})\end{array}$ & $\begin{array}{c}\text { Matrix effect } \\
(\text { mean } \pm \mathrm{SD})\end{array}$ \\
\hline Psoralidin & & \\
0.2 & $80.9 \pm 17.6$ & $82.7 \pm 16.4$ \\
0.4 & $87.3 \pm 10.8$ & $85.5 \pm 9.8$ \\
5 & $86.0 \pm 2.2$ & $93.5 \pm 3.4$ \\
200 & $91.8 \pm 4.7$ & $90.9 \pm 5.3$ \\
Alpinetin & & \\
$100 \mathrm{ng} / \mathrm{mL}$ & $82.0 \pm 8.8$ & $91.7 \pm 3.4$ \\
\hline
\end{tabular}

indicated that the recovery rate of protein precipitation (about $80 \%$ ) was higher than that of liquid-liquid extraction (about $60 \%)$.

3.2. Method Validation. Selectivity was determined using the chromatograms of blank plasma, blank plasma spiked with psoralidin and IS, and rat plasma after intragastric administration. Figure 2 shows no evident interference from endogenous substances at the retention times of psoralidin and the IS. The calibration curves of psoralidin were obtained in the concentration range from $0.2 \mathrm{ng} / \mathrm{mL}$ to $250 \mathrm{ng} / \mathrm{mL}$. The linear equation of the calibration curve of psoralidin was $y=5.28 \times 10^{-3} x+9.67 \times 10^{-3}\left(r^{2}=0.993\right)$. LOD and lower LOQ (LLOQ) of psoralidin were 0.06 and $0.2 \mathrm{ng} / \mathrm{mL}$, respectively. Extraction recoveries and matrix effects of psoralidin and the IS in rat plasma were summarized in Table 1. Extraction recoveries of psoralidin ranged from $80.9 \%$ to $91.8 \%$. The recovery of the IS was $82.0 \pm 8.8 \%$. The matrix effect of psoralidin and the IS ranged from $87.7 \%$ to $93.7 \%$ and $91.7 \pm 3.4 \%$, respectively. The intra- and interday precisions and accuracy of psoralidin in rat plasma were summarized in Table 2. The intra- and inter- day precisions of the QC samples were $<13.9 \%$ and $<13.4 \%$, respectively. The accuracy of the QC samples ranged from $97.5 \%$ to $112.9 \%$. The results demonstrated that the proposed method exhibited acceptable precision and accuracy. As shown in Table 3, psoralidin and the IS were stable in plasma at room temperature for $12 \mathrm{~h}$, at $4{ }^{\circ} \mathrm{C}$ for $24 \mathrm{~h}$, in 3 freeze-thaw cycles, and at $-20{ }^{\circ} \mathrm{C}$ for 2 weeks. In brief, these results indicated that the proposed method was reliable and acceptable.

Table 2. Intra- and inter-day precisions and accuracy for psoralidin in the QC samples in rat plasma

\begin{tabular}{lccccrc}
\hline $\begin{array}{l}\text { Nominal conc. } \\
(\mathrm{ng} / \mathrm{mL})\end{array}$ & $\begin{array}{c}\text { Intra-day concentration } \\
(\text { mean } \pm \mathrm{SD})\end{array}$ & $\begin{array}{c}\text { Precision RSD } \\
(\%)\end{array}$ & $\begin{array}{c}\text { Accuracy } \\
(\%)\end{array}$ & $\begin{array}{c}\text { Inter-day concentration } \\
(\text { mean } \pm \mathrm{SD})\end{array}$ & $\begin{array}{c}\text { Precision RSD } \\
(\%)\end{array}$ & $\begin{array}{c}\text { Accuracy } \\
(\%)\end{array}$ \\
\hline 0.2 & $0.22 \pm 0.03$ & 13.6 & 110.0 & $0.21 \pm 0.02$ & 9.5 & 105.0 \\
0.4 & $0.39 \pm 0.04$ & 10.3 & 97.5 & $0.41 \pm 0.05$ & 12.2 & 102.5 \\
5 & $5.6 \pm 0.63$ & 11.2 & 112.2 & $5.3 \pm 0.71$ & 13.4 & 106.0 \\
200 & $216.2 \pm 5.6$ & 2.6 & 108.1 & $225.7 \pm 11.9$ & 5.3 & 112.9 \\
\hline
\end{tabular}


Table 3. Stability of psoralidin in rat plasma (mean \pm SD)

\begin{tabular}{lcrr}
\hline Storage conditions & $\begin{array}{c}\text { Concentration } \\
(\mathrm{ng} / \mathrm{mL})\end{array}$ & $\begin{array}{c}\text { Measured } \\
(\mathrm{ng} / \mathrm{mL})\end{array}$ & $\begin{array}{r}\text { RSD } \\
(\%)\end{array}$ \\
\hline $25^{\circ} \mathrm{C}$ for $12 \mathrm{~h}$ & 0.4 & $0.43 \pm 0.04$ & 8.7 \\
& 5 & $6.8 \pm 0.61$ & 9.0 \\
Keeping at $4{ }^{\circ} \mathrm{C}$ for $24 \mathrm{~h}$ & 200 & $237.3 \pm 24.3$ & 10.2 \\
& 0.4 & $0.39 \pm 0.05$ & 12.8 \\
& 5 & $6.3 \pm 0.08$ & 1.3 \\
Three freeze-thaw cycles & 200 & $213.5 \pm 14.4$ & 6.8 \\
& 0.4 & $0.41 \pm 0.06$ & 14.6 \\
& 5 & $5.2 \pm 0.41$ & 7.9 \\
Long-term stability & 200 & $211.1 \pm 17.4$ & 8.3 \\
(at $-20^{\circ} \mathrm{C}$ for 15 days) & 0.4 & $0.42 \pm 0.04$ & 9.5 \\
& 5 & $5.8 \pm 0.38$ & 6.6 \\
& 200 & $211.2 \pm 11.4$ & 5.4 \\
\hline
\end{tabular}

3.3. Pharmacokinetics of Psoralidin in Rats. Figure 3 shows the plasma concentration-time profiles of psoralidin in rats after administration. Pharmacokinetic parameters (Table 4) were calculated using Drug and Statistics (DAS) version 3.0. The pharmacokinetic parameters of psoralidin in rats after intragastric administration were analyzed using twocompartment models. Psoralidin was absorbed into the blood circulation and reached the peak concentration at $4.0 \mathrm{~h}$.

As shown in Figure 3 and Table 4, it was found that plasma concentration of psoralidin was low after intragastric administration of 20 or $40 \mathrm{mg} / \mathrm{kg}$. The area under the curve was $\leq 190.9 \mu \mathrm{g} / \mathrm{L} \mathrm{h}$, indicating that it has lower absorption after intragastric administration. Studies have shown that the CYP2C19 enzyme is the main metabolic enzyme of psoralidin [25]. Psoralidin has a significant inhibitory effect on cytochrome P450 enzyme (CYP450) and UDP-glucuronyltransferase (UGT) $[23,26]$. When psoralidin was combined with other drugs, it should be noted that it can increase the plasma concentration of other drugs, thereby causing toxic side effects. The poor intragastric absorption of psoralidin may be related to its poor water solubility and can be modified by

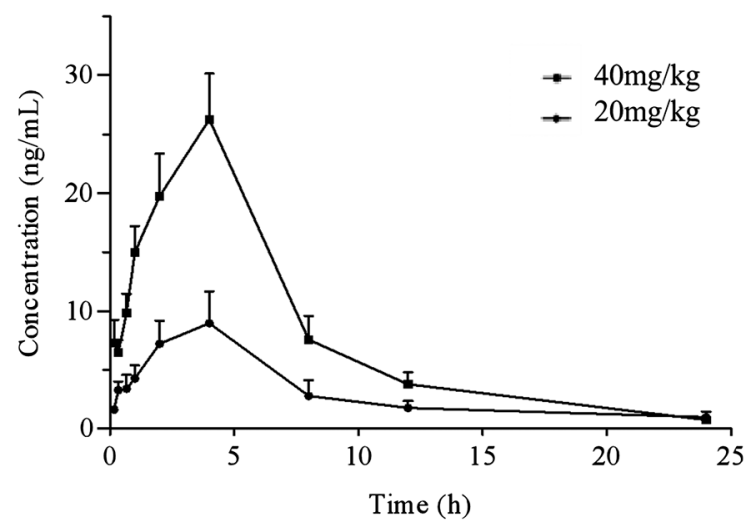

Figure 3. Mean plasma concentration-time of psoralidin after intragastric administration of 20 and $40 \mathrm{mg} / \mathrm{kg}$, respectively $(n=6)$

Table 4. The non-compartmental PK parameters of psoralidin after intragastric administration of 20 and $40 \mathrm{mg} / \mathrm{kg}$, respectively $(n=6)$

\begin{tabular}{lccc}
\hline Parameter & Units & $40 \mathrm{mg}$ & $20 \mathrm{mg}$ \\
\hline$t_{1 / 2}$ & $\mathrm{H}$ & $7.2 \pm 0.97$ & $7.1 \pm 0.27$ \\
$V$ & $\mathrm{~L} / \mathrm{kg}$ & $630.1 \pm 168.8$ & $600.1 \pm 138.8$ \\
$\mathrm{CL}$ & $\mathrm{L} / \mathrm{h} / \mathrm{kg}$ & $105.6 \pm 29.2$ & $100.6 \pm 22.2$ \\
$\mathrm{AUC}_{(0-\mathrm{t})}$ & $\mu \mathrm{g} / \mathrm{h}$ & $190.6 \pm 49.6$ & $90.6 \pm 4.6$ \\
$\mathrm{AUC}_{(0-\infty)}$ & $\mu \mathrm{g} / \mathrm{L} \mathrm{h}$ & $200.4 \pm 50.9$ & $95.4 \pm 5.9$ \\
$T_{\max }$ & $\mathrm{H}$ & $4.2 \pm 1.1$ & $4.0 \pm 1.1$ \\
$C_{\max }$ & $\mu \mathrm{g} / \mathrm{L}$ & $26.3 \pm 3.7$ & $9.5 \pm 2.7$ \\
\hline
\end{tabular}

enzymatic glycosylation to improve the water solubility and stability of psoralidin [27].

\section{Conclusion}

The validated UPLC-MS/MS method of analysis provided a rapid assay for the determination of psoralidin in rat plasma. The results demonstrated that the method was rapid, sensitive, and simple for the quantitative determination of psoralidin and was suitable for the pharmacokinetic studies of psoralidin in rats after intragastric administration of psoralidin at 20 and $40 \mathrm{mg} / \mathrm{kg}$. It was the first report about pharmacokinetic characteristic of psoralidin after intragastric administration. In addition, compared to previous assay methods, our method provides a shorter run time and is more sensitive.

\section{Conflict of Interest}

The authors declare that they have no conflict of interest associated with this publication, and there has been no significant financial support for this work that could have influenced its outcome.

Acknowledgements. This work was supported by the National Natural Science Foundation of China [grant numbers 81773691 and 81703815] and Wenzhou Science and Technology Major Project, China [grant number ZS2017018].

\section{References}

1. Lin, Q.; Li, J.; Li, H. J. Xianning University 2012, 26, 175-177.

2. Pahari, P.; Saikia, U. P.; Das, T. P.; Damodaran, C.; Rohr, J. Tetrahedron 2016, 72, 3324-3334.

3. Hao, W. H.; Zhang, X. N.; Zhao, W. W.; Chen, X. P. PeerJ 2014, 2.

4. Wang, X.; Xu, C.; Hua, Y.; Sun, L.; Cheng, K.; Jia, Z.; Han, Y.; Dong, J.; Cui, Y.; Yang, Z. J. Exp. Clin. Cancer Res. 2016, 35, 186.

5. Jin, Z. L.; Yan, W.; Jin, H.; Ge, C. Z.; Xu, Y. H. Oncol. Lett. 2016, 12, 971-976.

6. Sowmyalakshmi, S.; Kumar, R.; Pahari, P.; Rohr, J.; Damodaran, C. Cancer Res. 2010, 70.

7. Damodaran, C.; Kumar, R.; Rohr, J. Cancer Res. 2010, 70.

8. Wang, D.; Li, F.; Jiang, Z. Planta Med. 2001, 67, 748-9.

9. Zhai, Y. K.; Li, Y. Y.; Wang, Y. P.; Cui, J. W.; Feng, K.; Kong, X. J.; Chen, L. Eur. J. Pharmacol. 2017, 801, 62-71.

10. Zhai, Y. K.; Wang, Q. F.; Li, Y. Y.; Cui, J.; Feng, K.; Kong, X. J.; Xian, C. J. Biomed. Pharmacother. 2018, 102, 1015-1024.

11. Rao, Z. T.; Wang, S. Q.; Wang, J. Q. Mol. Med. Rep. 2018, 17, 3418 3424.

12. Kong, L. B.; Ma, R.; Yang, X. B.; Zhu, Z. Q.; Guo, H.; He, B. R.; Wang, B.; Hao, D. J. Int. Immunopharmacol. 2017, 51, 31-39.

13. Ren, G. W.; Luo, W. W.; Sun, W.; Niu, Y. A.; Ma, D. L.; Leung, C. H.; Wang, Y. T.; Lu, J. J.; Chen, X. P. Phytomedicine 2016, 23, 939-947.

14. Chen, X.; Zhang, X.; Hao, W.; Lu, J. Basic Clin. Pharmacol. 2014, $115,314-314$

15. Zhang, R.; Shi, W.; Li, L.; Huang, X.; Xu, D.; Wu, L. Pharmazie 2019 $74,67-72$.

16. Fasheng, L.; Guang, Y.; Xu, H. Zhongguo Yaoshi 2008, 11, 140-142.

17. Szliszka, E.; Czuba, Z. P.; Sędek, Ł.; Paradysz, A.; Król, W. Pharmacol Rep 2011, 63, 139-148.

18. Hao, W.; Zhang, X.; Zhao, W.; Chen, X. PeerJ 2014, 2, e555.

19. Jin, Z.; Yan, W.; Jin, H.; Ge, C.; Xu, Y. Oncol. Lett. 2016, 12, 971976.

20. Wang, T.; Yin, Z.; Zhang, W. Zhongguo Zhongyao Zazhi 2013, 38, 2328-2333.

21. Li, J.; Wang, X.; Zeng, Y. Zhongguo Zhongyao Zazhi 2013, 38, 18161819.

22. Yang, Y. F.; Zhang, Y. B.; Chen, Z. J.; Zhang, Y. T.; Yang, X. W. Phytomedicine 2018, 38, 166-174.

23. Shi, X. B.; Zhang, G.; Mackie, B.; Yang, S. M.; Wang, J.; Shan, L. N. J. Chromatogr. B 2016, 1029, 145-156.

24. Administration, F. a. D. Bioanalytical Method Validation Guidance for Industry, USA, 2018.

25. Shi, X. Study on the metabolism of morin and Psoralen in vitro, China Medical University, Shenyang, 2015.

26. Li, M. Inhibition of Fructus psoralen on uridine two phosphate glucuronosyltransferase (UGT), Liaoning Medical University, Jinzhou, 2015.

27. Dietrich, S.; Floegel, A.; Troll, M.; Kuhn, T.; Rathmann, W.; Peters, A.; Sookthai, D.; von Bergen, M.; Kaaks, R.; Adamski, J.; Prehn, C.; Boeing, H.; Schulze, M. B.; Illig, T.; Pischon, T.; Knuppel, S.; Wang-Sattler, R.; Drogan,

D. Int. J. Epidemiol. 2016, 45, 1406-1420. 